\title{
A TOMADA DE DECISÃO APOIADA: O NOVO PROCEDIMENTO DE JURISDIÇÃO VOLUNTÁRIA
}

\section{THE SUPPORTED DECISION-MAKING: THE NEW VOLUNTARY JURISDICTION PROCEDURE}

José Miguel Garcia Medina ${ }^{1}$

Thamirys Silveira Martin ${ }^{2}$

\section{RESUMO}

A deficiência na antiguidade era tratada com discriminação, pessoas portadoras de necessidades especiais nao tinham o respeito dos demais, a incapacidade era sinônimo de deficiência. Porém, no período pós guerra, com inúmeros feridos, buscou-se a reabilitação destes, fato que encejou uma mudança de paradigma. Atualmente, recentes modificações ampliaram a chamada Teoria das Incapacidades, reconhecendo para estas a incapacidade relativa, nos termos do Artigo $4^{\circ}$, inciso III do referido código, cuja redação fora dada pela Lei 13.146/2015, também conhecida como Estatuto da Pessoa com Deficiência. Dessa forma, a predita lei ao criar o instituto da Tomada de Decisão Apoiada apresenta nova medida capaz de beneficiar os portadores de necessidades especiais, e por meio da jurisdição voluntária permitiu a autonomia necessária para requererem o referido instituto. PALAVRA CHAVE: Decisão Apoiada. Deficiência. Jurisdição Voluntária. Estatuto da Pessoa com Deficiência. Código Civil.

\begin{abstract}
Disability in seniority was treated with discrimination, people with disabilities had no respect for others, disability was synonymous with disability. However, in the postwar period, with many injured, they sought to rehabilitate them, a fact that led to a paradigm shift. Currently, recent modifications have expanded the so-called Disability Theory, recognizing for them the relative disability, under the terms of Article 4, item III of the aforementioned code, whose wording was given by Law 13.146 / 2015, also known as the Statute of the Disabled. Thus, the predicted law when creating the Institute of Supported Decision Making presents a new measure capable of benefiting the

\footnotetext{
${ }^{1}$ Doutor e Mestre em Direito pela PUC-SP. Professor do Mestrado em Direito Processual e Cidadania da Unipar. Advogado. medina@medina.adv.br

2 Graduanda do $5^{\mathrm{o}}$ ano. Universidade: Universidade Paranaense - UNIPAR. E-mail: thamiryssm@gmail.com
} 
handicapped, and through voluntary jurisdiction allowed the necessary autonomy to apply for this institute.

KEYWORD: Decision Supported. Deficiency. Voluntary Jurisdiction. Statute of Persons with Disabilities. Civil Code. 


\section{CONTEXTO HISTÓRICO}

Considerando o tema em análise, é necessário abordar aspectos históricos a respeito das pessoas com deficiência, e assim transitar em contextos culturais diferentes. A forma como tais pessoas foram e são percebidas na sociedade se modificou ao longo dos anos, percorrendo um trajeto tanto de evoluções como de retrocessos.

Nos primórdios, as pessoas nascidas com algum tipo de anomalia eram discriminadas, isso quando as deixavam viver. Por exemplo, em Roma no período da Idade Média permitia-se o sacrifício dos filhos nascidos com deficiência, tais nascimentos eram vistos pelo povo como uma punição divina ou ainda, consideravam os deficientes como bruxos, motivo pelo qual os nascidos dessa forma eram desamparados. ${ }^{3}$

Entre o período do século XIX e XX, houve incisiva apelação para isolar as pessoas com deficiência, mediante a criação de entidades visando separá-las das demais pessoas, inexistindo anseio pela integração social, em razão de não servirem para o trabalho. ${ }^{4}$

A ausência de reconhecimento como pessoas, as tornavam invisíveis perante a sociedade, fator capaz de gerar sofrimento físico e psíquico, principalmente nestes períodos em que não havia reconhecimento de direitos humanos, resultava por permitir que a própria lei estabelecesse crueldades. Inexistindo leis a beneficiar os deficientes. ${ }^{5}$

Conforme expressa Gustavo Martins Piccolo e Enicéia Gonçalves Mendes: “anteriormente a Idade Moderna o deficiente era tido como monstro. Este era seu estigma, sua marca. Não havia deficientes porque simplesmente a etimologia sequer existia à época". ${ }^{6}$ Em que pese a história retratar espetáculos nas cortes, onde as pessoas com

\footnotetext{
${ }^{3}$ MONTEIRO, Carlos Medeiros et al. Pessoa com deficiência: a história do passado ao presente. Revista internacional de audición y lenguaje, logopedia, apoyo a la integración y multiculturalidad, Espanha, v. 2, n.3, p.222/223, jul. 2016. $<$ https://revistaselectronicas.ujaen.es/index.php/riai/article/view/4231/3456> Acesso em 10 de agosto de 2019.

${ }^{4}$ SOUZA, Sirleine Brandão. Deficiência: a trajetória de uma concepção. Journal of Research in Special Educational Needs, v. 16, n. 1, p, 366, 2016. Disponível em: <https://onlinelibrary.wiley.com/doi/pdf/10.1111/1471-3802.12297.> Acesso em 11 de agosto de 2019.

${ }^{5}$ MONTEIRO, Carlos Medeiros et al. Pessoa com deficiência: a história do passado ao presente. Revista internacional de audición y lenguaje, logopedia, apoyo a la integración y multiculturalidad, Espanha, v. 2, n.3, p.222/223, jul. $2016 . \quad$ Disponível em: <https://revistaselectronicas.ujaen.es/index.php/riai/article/view/4231/3456> Acesso em 10 de agosto de 2019.

${ }^{6}$ PICCOLO, Gustavo Martins; MENDES, Enicéia Gonçalves. Nas pegadas da história: tracejando relações entre deficiência e sociedade. Revista Educação Especial, Santa Maria, p. 32, mar. 2012. ISSN 
alguma anomalia, eram expostas para entreter e divertir o público, ainda assim, o legítimo reconhecimento como pessoa e cidadão não era efetivo.

Nos dizeres de Garcia, a deficiência sob o olhar dos séculos, é assim compreendida: "Entretanto é o discurso clínico do século XIX quem levará a deficiência, a ser entendida pela sociedade do século XX, como uma desgraça humana, prova da degenerescência do homem, da contaminação do sangue, da invalidez e da monstruosidade hereditária. É pelo discurso clínico que a deficiência deixará de ser fruto da imaginação, para passar a ser uma representação social. Uma categoria de seres humanos que possuem um déficit. Essa forma de pensar a deficiência se dissemina de modo rápido no século $\mathrm{XX}$, porque as experiências médicas vão afirmar que as raízes da deficiência humana estão calcadas na decadência da raça". 7

A bíblia em seus escritos do antigo testamento, relata que o povo hebreu via a deficiência como algo sacrílego. ${ }^{8}$ Contudo, o oposto se verifica com o crescimento do cristianismo, em que a pessoa com deficiência não é mais vista como um castigo de Deus, passando a ser reconhecida como pessoa que merece tratamento adequado. ${ }^{9}$

Avançando no tempo, os períodos após a $1^{\mathrm{a}}$ e $2^{\mathrm{a}}$ Guerra Mundial retratam uma mudança de paradigma, surge a preocupação com os feridos, visando a reabilitação daqueles que sofreram com a guerra, permitindo a reinserção na sociedade. ${ }^{10}$ Fator que representa nova visão sobre a deficiência, não sendo mais entendida como uma incapacidade, mas como uma forma diversa de viver.

<https://periodicos.ufsm.br/educacaoespecial/article/view/4611/3091>. Acesso em: 18 ago. 2019. doi:http://dx.doi.org/10.5902/1984686X4611.

${ }^{7}$ GARCIA, Eduardo de Campos. Deficiência: gênese e crítica de um conceito. 2011. 245 f. Dissertação (Mestrado em Educação, Arte e História) - Universidade Presbiteriana Mackenzie, São Paulo, p. 74, 2011. Disponível em: <http://tede.mackenzie.br/jspui/handle/tede/1838>. Acesso em: 01 ago. 2019.

${ }^{8}$ COSCODAI, Beatriz Teresinha. Quando uma diferença é posta como deficiência: Reflexões sobre três histórias. Dissertação de Mestrado em Educação - Universidade Federal de Santa Catarina. Florianópolis-SC, $\quad$ p. $17 . \quad 1994 . \quad$ Disponível $\quad$ em: https://repositorio.ufsc.br/xmlui/bitstream/handle/123456789/76135/97201.pdf?sequence=1\&isAllowe d=y> Acesso em: 02 ago. 2019.

${ }^{9}$ MONTEIRO, Carlos Medeiros et al. Pessoa com deficiência: a história do passado ao presente. Revista internacional de audición y lenguaje, logopedia, apoyo a la integración y multiculturalidad, Espanha, v. 2, n. 3, p. 222/223, jul. 2016. Disponível em: <https://revistaselectronicas.ujaen.es/index.php/riai/article/view/4231/3456> Acesso em 10 de agosto de 2019.

${ }^{10}$ SOUZA, Sirleine Brandão. Deficiência: a trajetória de uma concepção. Journal of Research in Special Educational Needs, v. 16, n. 1, p, 366, 2016. Disponível em: <https://onlinelibrary.wiley.com/doi/pdf/10.1111/1471-3802.12297.> Acesso em 11 de agosto de 2019. 
Atualmente, o Código Civil Brasileiro e o Estatuto da Pessoa com Deficiência proporcionaram às pessoas com algum tipo de limitação o reconhecimento como pessoas dotadas de capacidade e ampla manifestação de vontade, para decidirem sobre suas vidas, conforme será visto no decorrer do trabalho.

\section{CAPACIDADE CIVIL - DESDOBRAMENTOS}

A definição de capacidade pode ser compreendida como "aptidão, competência", razão pela qual o Código Civil estabelece em seu capítulo I, a denominação capacidade para definir os sujeitos providos de direitos e deveres perante a ordem civil, conforme prevê o Artigo $1^{\circ}$.

No entanto, relativamente às pessoas com deficiência, recentes modificações ampliaram a chamada Teoria das Incapacidades, reconhecendo para estas a incapacidade relativa, nos termos do Artigo $4^{\circ}$, inciso III do referido código, cuja redação fora dada pela Lei 13.146/2015, também conhecida como Estatuto da Pessoa com Deficiência.

O supramencionado inciso III, proporciona àqueles que anteriormente eram considerados absolutamente incapazes, o reconhecimento de sua condição de pessoa apta a exteriorizar sua vontade, mesmo portando algumas limitações, ressaltando, por exemplo em casos de interdição, o curador não se sub-roga nos direitos do curatelado, todavia, suas ações restam condicionadas à vontade do legítimo detentor do direito. Assim, o relativamente incapaz não será representado, mas assistido. ${ }^{11}$

As referidas alterações legislativas, tem o escopo de manter a independência do deficiente, conforme expressa Fiuza "O objetivo da Lei é, evidentemente, o de preservar, ao máximo, na medida do possível, a autonomia do deficiente, respeitadas as limitações do caso concreto." $" 12$

Nessa conjuntura a assistência é utilizada para assistir os relativamente incapazes, incluindo os portadores de deficiências. Não obstante, se verifica que nem todos os

\footnotetext{
${ }^{11}$ JUNIOR, Nelson Nery. Código Civil Comentado. Ed. 2017. Revista dos Tribunais. Código Civil, Parte Geral, Livro I Das Pessoas, Título I Das Pessoas Naturais, Capítulo I Da Personalidade e da Capacidade. Comentário ao Artigo $4^{\circ}$. Disponível em <https://proview.thomsonreuters.com/launchapp/title/rt/codigos/100083938/v12/document/124277275 C.I_TIT.I_L.I_PT.GR/anchor/a-A.4> Acesso em: 04 ago. 2019.

${ }^{12}$ FIUZA, Cézar. Direito Civil: Curso Completo. Ed. 2016. Revista dos Tribunais. CAPÍTULO IV. PESSOAS. Disponível em <https://proview.thomsonreuters.com/launchapp/title/rt/monografias/96371818/v18/document/109578 523/anchor/a-109578523> Acesso em: 04 ago. 2019.
} 
deficientes se enquadram na predita condição de incapacidade, assim, o instituto da tomada de decisão apoiada surgiu para somar aos modos de auxílio a serem prestados àqueles que possuem alguma limitação (buscar sinônimo), inclusive (buscar sinônimo) acrescer aos processos de jurisdição voluntária, nova modalidade de ação.

Justifica-se a afirmação acima, haja vista que nos casos de incapacidade relativa, de regra utilizava-se a ação de interdição para que o relativamente incapaz pudesse ser assistido (representado) nos atos da vida civil. Destarte, é possível compreender que a recente modalidade de ação, considera situações de pessoas com deficiência que possuem amplo discernimento, porém, que devido a alguma limitação física, podem necessitar de um auxílio no momento de realizar algum negócio.

Nesse sentido, o ideal de incapacidade anteriormente existente às supramencionadas alterações restou ampliado, restringindo a incapacidade absoluta pelo critério etário, ou seja, menores de 18 anos, impulsionando as demais condições de incapacidade absoluta para enquadramento em incapacidade relativa, permitindo maior inserção.

Desse modo, juntamente com a ampliação da incapacidade relativa, o Estatuto da Pessoa com Deficiência possibilita a assistência de pessoas com limitações físicas ao instituir a tomada de decisão apoiada.

\section{CONCEITO DA TOMADA DE DECISÃO APOIADA}

A Lei 13.146/2015, denominada Estatuto da Pessoa com Deficiência, inovou trazendo o instituto da tomada de decisão apoiada em seu artigo 116, que acresceu ao Código Civil o capítulo III, tratando do tema no Artigo 1.783-A.

O conceito previsto no referido capítulo define este instituto como o processo autônomo impetrado pela pessoa com deficiência, com intuito de nomear duas pessoas a fim de lhe apoiar em situações da vida civil.

O estatuto da pessoa com deficiência procurando se adequar à Convenção sobre os Direitos da pessoa com deficiência, ratificada pelo congresso Nacional, promove uma forma diversa de incitar a autonomia.

De acordo com o Conselho Nacional do Ministério Público (2016), a tomada de decisão apoiada pode ser entendida como: "É um processo judicial criado pela Lei Brasileira de Inclusão para garantir apoio à pessoa com deficiência em suas decisões sobre atos da vida civil e assim ter os dados e informações necessários para o pleno exercício 
de seus direitos. É um processo autônomo, com rito próprio, no qual a própria pessoa com deficiência indica os apoiadores de sua confiança a serem nomeados pelo juiz. Do processo judicial de tomada de decisão apoiada participam, além da parte interessada e das duas pessoas apoiadoras, o juiz, que é assistido por uma equipe multidisciplinar, e o Ministério Público". ${ }^{13}$

Dessa forma, amplia-se as opções de proteção àqueles que possuem alguma deficiência, sem necessitar de um processo de interdição, que deve ser visto como exceção em nosso ordenamento, por ser medida mais gravosa, ainda que a nova dicção do Código de Processo Civil retrate para os casos de interdição pessoas com incapacidade relativa.

Anteriormente por não existir outra medida a fim de auxiliar pessoas com certa deficiência, seja física ou mental, o instituto mais utilizado era o da ação de curatela, de modo que a pessoa era interditada, mesmo em situações de plena cognição e manifestação da vontade.

Insta mencionar que a tutela e a curatela estabelecem a presunção de incapacidade da pessoa, por outro lado, a tomada de decisão apoiada presume a capacidade da pessoa com deficiência, pois será a única legitimada a impetrar com a ação em seu favor. ${ }^{14}$

A inovação legislativa apresenta nova oportunidade aos deficientes, de modo a contribuir na realização de seus atos da vida civil, fazendo com que, mediante a livre escolha de pessoas de sua confiança possa receber assistência no momento de celebrar um negócio jurídico. Considerando os dizeres de Marcos Ehrhardt Junior e Bruno Oliveira de Paula Batista, "Com a tomada de decisão apoiada, o respeito à autodeterminação da pessoa com deficiência é muito maior, pois além de haver necessidade de iniciativa do próprio apoiado, é este quem escolherá seus apoiadores."15

\footnotetext{
${ }^{13}$ Conselho Nacional do Ministério Público. Tomada de decisão apoiada e curatela: medidas de apoio previstas na Lei Brasileira de Inclusão da Pessoa com Deficiência. Brasília: CNMP, 2016. 27 p. il. Disponível em: < http://www.cnmp.mp.br/portal/images/curatela.pdf> Acesso em 05 ago. 2019.

14 GABURRI, Fernando. CAPACIDADE E TOMADA DE DECISÃO APOIADA: IMPLICAÇÕES DO ESTATUTO DA PESSOA COM DEFICIÊNCIA NO DIREITO CIVIL. Direito e Desenvolvimento, Centro Universitário de João Pessoa, v. 7, n. 13, p. 130, 12 jun. 2017. Disponível em: <https://periodicos.unipe.br/index.php/direitoedesenvolvimento/article/view/304/286> Acesso em: 05 ago. 2019.

15 JUNIOR, Marcos Ehrhardt; BATISTA, Bruno Oliveira de Paula. O NEGÓCIO JURÍDICO PROCESSUAL CELEBRADO PELA PESSOA COM DEFICIENCIA E A TOMADA DE DECISÃO APOIADA. REVISTA DIREITO E JUSTIÇA: REFLEXÕES SOCIOJURÍDICAS, [S.1.], v. 18, n. 31, p. 70, ago. 2018. ISSN 21782466. Disponível em: <http://srvapp2s.santoangelo.uri.br/seer/index.php/direito_e_justica/article/view/2451/1256>. Acesso em: 18 Ago. 2019. doi:http://dx.doi.org/10.31512/rdj.v18i31.2451.
} 
Nesse sentido, à luz do princípio basilar do ordenamento brasileiro, constata-se a observância da Dignidade da Pessoa Humana, a valorização da independência de cada pessoa ao relativizar a teoria das incapacidades, retirando a concepção de incapacidade total, avançando até alcançar o ideal trazido na criação da tomada de decisão apoiada, permitindo a exteriorização da vontade da pessoa com deficiência.

\section{A JURISDIÇÃO VOLUNTÁRIA}

O Código de Processo Civil não apresenta disposição específica quanto ao processo da tomada de decisão apoiada, assim, por se enquadrar dentro dos procedimentos de jurisdição voluntária, se assemelha ao processo de interdição.

Sendo essencial antes de tratar do referido processo, expor uma breve introdução a respeito da jurisdição. Neste contexto, a jurisdição tem o compromisso de estabelecer a proteção eficaz ao caso concreto nos termos da legislação pertinente, dessa forma, segundo Bruno Cavalcanti Angelin Mendes a jurisdição possui o seguinte dever: “[...] latente o dever da Jurisdição no sentido de promoção da tutela efetiva, no que tange à obtenção de um resultado prático de acordo com o direito material, tendo como pressuposto básico a atuação do legislador no sentido de constituir procedimentos e técnicas processuais executivas aptas ao exercício do direito em questão de modo eficaz. Ao juiz incumbirá, então, a tarefa de interpretar a norma processual de acordo com as particularidades do caso concreto a fim de identificar qual a técnica que melhor atenderá aos anseios de efetividade do direito material."16

Destarte, tendo em vista que uma das espécies da jurisdição é a chamada jurisdição voluntária, como predito, tratar-se-á desta no procedimento da tomada de decisão apoiada. Se caracterizando à luz do princípio da legalidade, como o exercício estatal realizado por meio do juiz, a fim de convalidar determinados atos da vida privada. ${ }^{17}$

16 MENDES, Bruno Cavalcanti Angelin. A JURISDIÇÃo NO ESTADO CONSTITUCIONAL. REVISTA DIREITO E JUSTIÇA: REFLEXÕES SOCIOJURÍDICAS, [S.1.], v. 16 , n. 26, p. 152-169, mai. 2016. ISSN 21782466. Disponível em: <http://srvapp2s.santoangelo.uri.br/seer/index.php/direito_e_justica/article/view/1158/862>. Acesso em: 18 Ago. 2019. doi:http://dx.doi.org/10.31512/rdj.v16i26.1158.

${ }^{17}$ ALVIM, Tereza Arruda et. al. Breves comentários ao novo Código de Processo Civil. Ed. 2015. Revista dos Tribunais. Parte especial, Livro I - Do processo de conhecimento e do cumprimento de sentença, Título III - Dos procedimentos especiais, Capítulo XV. DOS PROCEDIMENTOS DE JURISDIÇÃO VOLUNTÁRIA. Disponível em: <https://proview.thomsonreuters.com/launchapp/title/rt/monografias/101497668/v1/document/106304 607/anchor/a-106304607> Acesso em: 05 ago. 2019. 
Em relação ao seu significado a doutrina diverge de entendimento, a compreendendo como mera atuação administrativa e não como atuação jurisdicional propriamente dita. De acordo com o entendimento de José Miguel Garcia Medina, a jurisdição voluntária difere-se da jurisdição contenciosa no seguinte sentido: “[...] em procedimentos de jurisdição voluntária, está-se, no mais das vezes, diante de hipóteses em que não se realiza, substancialmente, a função jurisdicional, mas apenas formalmente. Usando outra forma de se expressar, pode-se afirmar que a jurisdição contenciosa é função jurisdicional constitucionalmente necessária, enquanto a jurisdição voluntária é função jurisdicional constitucionalmente não necessária." 18

Todavia, independente do posicionamento adotado, a função jurisdicional exercida nas ações ausentes de litigiosidade, é imprescindível aos atos da vida privada, justamente no intuito de estabelecer a fiscalização do Estado em situações que envolvam pessoas com necessidades especiais, como na tomada de decisão apoiada, estabelecendo dessa forma, ampla relação com os preceitos descritos na Constituição Federal. Dentre os preditos preceitos, está o princípio basilar da dignidade da pessoa humana, insculpido no Artigo $1^{\circ}$, inciso III da referida carta magna.

Consoante a disposição do supracitado princípio, o que significa a dignidade da pessoa humana? Primeiramente, pode ser compreendida quanto a acepção de importância inerente a cada pessoa, retrata, portanto, o axioma central do ordenamento brasileiro, estando acima de qualquer outro valor. ${ }^{19}$

Em que pese o Brasil ser signatário de convenções e tratados internacionais que versem sobre direitos humanos, aponta-se como a maior justificativa para a regulamentação do Estatuto da Pessoa com Deficiência, por meio da Lei no 13.146/2015, o fato da Convenção sobre os Direitos das Pessoas com Deficiência retratar pressupostos que vão de encontro aos interesses da Constituição Federal.

\footnotetext{
${ }^{18}$ MEDINA, José Miguel Garcia. Curso de Direito Processual Civil Moderno. Ed. 2018. Revista dos Tribunais. CAPÍTULO I. PARTE GERAL. CAPÍTULO IV. PROCEDIMENTOS ESPECIAIS DE JURISDIÇÃO CONTENCIOSA E VOLUNTÁRIA. Disponível em: <https://proview.thomsonreuters.com/launchapp/title/rt/monografias/104783476/v4/document/147364 227/anchor/a-147364227> Acesso em: 06 ago. 2019.
}

19 ALVES, Rosa Maria Guimarães. O PRINCíPIO DA DIGNIDADE DA PESSOA HUMANA. Colloquium Humanarum. ISSN: 1809-8207, v. 6, n. 2, p. 33, 2009. Disponível em: <http://revistas.unoeste.br/index.php/ch/article/view/456/445> Acesso em: 06 ago. 2019. 


\section{O PROCEDIMENTO DA TOMADA DE DECISÃO APOIADA}

Observando as disposições trazidas ao Código Civil no Artigo 1.783-A, a pessoa com deficiência tem a autonomia de escolha ao permitir a nomeação de duas pessoas que lhe são confiáveis, no intuito receber um aconselhamento nos atos que considere importantes.

O mesmo caput salienta o dever dos apoiadores de prover o apoiado de esclarecimentos imprescindíveis no ato da celebração de um negócio jurídico. Esse dever está ligado diretamente ao exercício da capacidade do apoiado, entretanto não se pode conceber que a capacidade deste está subordinada ao apoiador, principalmente em razão da nova concepção de capacidade trazida ao Código Civil, consoante Marcos Ehrhardt Junior e Bruno Oliveira de Paula Batista "entende-se que a pessoa apoiada não tem sua capacidade afetada por conta do procedimento da TDA, de maneira que ela não perderá sua capacidade, tampouco terá reduzido tal atributo". ${ }^{20}$

Segundo o parágrafo $1^{\circ}$ (primeiro) do artigo 1.783-A do mencionado código, para que exista a formalização deste ato é preciso, antes do requerimento, que as partes (apoiado e apoiadores) façam um termo tratando os limites, prerrogativas e período de duração deste instituto.

Posteriormente a formalização do termo, a pessoa com deficiência o apresentará no momento de impetrar com a ação. Restando clara a autonomia e independência deste instituto no parágrafo $2^{\circ}$ (segundo) do artigo em análise, ao expressar que a pessoa legitimada para entrar com o processo é a própria pessoa a ser apoiada.

Assemelha-se ao procedimento da curatela, pois o magistrado somente dará o veredito após o acompanhamento de equipe multidisciplinar, de acordo com o parágrafo $3^{\circ}$ do Artigo 1.783-A do Código Civil, ou seja, além da participação obrigatória do Ministério Público, é preciso que profissionais como um assistente social, presencie o processo a fim de verificar se o instituto atende as necessidades do interessado.

\footnotetext{
${ }^{20}$ JUNIOR, Marcos Ehrhardt; BATISTA, Bruno Oliveira de Paula. O NEGÓCIO JURÍDICO PROCESSUAL CELEBRADO PELA PESSOA COM DEFICIÊNCIA E A TOMADA DE DECISÃO APOIADA. REVISTA DIREITO E JUSTIÇA: REFLEXÕES SOCIOJURÍDICAS, [S.1.], v. 18, n. 31, p. 70, ago. 2018. ISSN 21782466. Disponível em: <http://srvapp2s.santoangelo.uri.br/seer/index.php/direito_e_justica/article/view/2451/1256>. Acesso em: 18 Ago. 2019. doi:http://dx.doi.org/10.31512/rdj.v18i31.2451.
} 
O objetivo maior é a proteção da pessoa portadora de necessidades especiais, para tanto, é preciso que o tramite processual seja complexo para verificar se realmente a tomada de decisão apoiada será a medida mais adequada ao caso.

Citando o escólio de José Miguel Garcia Medina, ao tratar da tomada de decisão apoiada, profere as seguintes considerações: “A tomada de decisão apoiada, a nosso ver, é figura que se aproxima mais da assistência que da curatela, mas que com elas não se confunde. No caso, busca-se o apoio para que a própria pessoa com deficiência exerça sua capacidade (cf. art. 1.783-A, caput, do CC/2002), em relação a certos atos. Como a curatela tornou-se medida mais restrita, a partir da Lei 13.146/2015, pode suceder, a depender do teor do pedido de definição dos termos da curatela, que mostre-se mais adequado o processo de tomada de decisão apoiada." 21

Um dos pontos interessantes desse instituto, que revela o intuito de proteção, é que em caso das partes divergirem de opinião quanto a celebração de algum negócio, que possa acarretar efeitos lesivos ao interessado, o juiz é quem irá decidir ouvido o representante do Ministério Público (Artigo 1.783-A, parágrafo $6^{\circ}$ do Código Civil).

Logo, o papel dos apoiadores é de trazer segurança e auxílio ao apoiado, visando o interesse deste, tendo o dever de comunicar o magistrado quanto a negócios que possam trazer algum dano à pessoa com deficiência. ${ }^{22}$

Ainda, para ambas as partes é possível, a qualquer tempo, requerer o término do instituto no caso do apoiado, ou a exclusão do instituto no caso do apoiador, nos termos do Artigo 1783-A, parágrafos $9^{\circ}$ e $10^{\circ}$ do Código Civil, no entanto, a respeito do apoiador o seu pedido passará pelo exame do magistrado.

Cabível ressaltar, em razão da finalidade deste instituto, que qualquer pessoa, além do apoiado, poderá oferecer denúncia ao Ministério Público ou ao juiz, caso o apoiador não cumpra com os seus deveres (Artigo 1.783-A, parágrafo $7^{\circ}$ do Código Civil).

Portanto, a tomada de decisão apoiada, apesar de disciplinada em um único artigo, apresenta grandes considerações e mudanças quanto as medidas que podem ser utilizadas

\footnotetext{
${ }^{21}$ MEDINA, José Miguel Garcia. Curso de Direito Processual Civil Moderno. Ed. 2018. Revista dos Tribunais. CAPÍTULO I. PARTE GERAL. CAPÍTULO IV. PROCEDIMENTOS ESPECIAIS DE JURISDIÇÃO CONTENCIOSA E VOLUNTÁRIA. Disponível em: <https://proview.thomsonreuters.com/launchapp/title/rt/monografias/104783476/v4/document/147364227 /anchor/a-147364227> Acesso em: 06 ago. 2019.

${ }^{22}$ KATZ, Bruna; TEDESCO, Raquel. Capacidade Civil da Pessoa com Deficiência: Tomada de Decisão Apoiada e Curatela. Migalhas, 2018. Disponível em: https://www.migalhas.com.br/dePeso/16,MI278658,61044-

Capacidade+Civil+da+Pessoa+com+Deficiencia+Tomada+de+Decisao+Apoiada> Acesso em: 06 de ago. 2019.
} 
para assegurar os interesses de pessoas com deficiência, e somada ao Estatuto da Pessoa com Deficiência revela o reconhecimento da independência de cada pessoa, ainda que presentes algumas limitações.

\section{CONCLUSÃO}

Assim sendo, é possível compreender através de uma sequência lógica abordada neste trabalho, que a deficiência ao longo dos anos foi vista de diferentes formas, tanto positiva como negativamente por meio de discriminações e adjetivos pejorativos. Inexistia proteção, antes de acontecimentos drásticos como as grandes guerras mundiais, somente após estas um novo olhar surge, aquele capaz de enxergar a igualdade e reabilitação.

A questão da capacidade civil, o reconhecimento da autonomia e independência das pessoas portadoras de necessidades especiais, infelizmente ocorreu apenas agora, fator que revela o descaso ao longo dos tempos com aqueles considerados diferentes da maioria populacional. Não obstante o tardar na inovação, jubiloso é o fato desta ter ocorrido.

O Estatuto da Pessoa com Deficiência trouxe premissas essenciais aos seus beneficiados, apresentou proposta capaz de modificar todo o conceito de capacidade até então existente, e foi exitoso em apresentar a Tomada de Decisão Apoiada como medida a estabelecer auxílio sem retirar a independência e liberdade da pessoa apoiada.

Disciplinando o instituto nos moldes da jurisdição voluntária, e legitimando a própria pessoa com deficiência a requerer o apoio.

\section{REFERÊNCIAS}

JUNIOR, Augusto Jaeger; BARCELLOS, Nicole Rinaldi de. COMPARATIVE TRANSNATIONAL CIVIL PROCEDURE: EXCLUSIVE AND EXORBITANT CIVIL JURISDICTION IN BRAZIL, UNITED STATES OF AMERICA AND EUROPEAN UNION. Revista Juridica, [S.1.], v. 1, n. 54, p. 73 - 96, mar. 2019. ISSN 2316-753X. Disponível em: <http://revista.unicuritiba.edu.br/index.php/RevJur/article/view/3301/371371794>.

Acesso em: 23 abr. 2020. doi:http://dx.doi.org/10.21902/revistajur.2316753X.v1i54.3301.

NASCIMENTO, Valéria Ribas do; PEREIRA, Marília do Nascimento. A ATIVIDADE JURISDICIONAL COMO PARADIGMA PARA A CONSOLIDAÇÃO DEMOCRÁTICA: A (NÃO) SUPERAÇÃO DO ATIVISMO JUDICIAL PARA A CONSTRUÇÃO DE UMA JURISDIÇÃO CONSTITUCIONAL. Revista Juridica, 
[S.1.], v. 4, n. 45, p. 565 - 585, fev. 2017. ISSN 2316-753X. Disponível em: <http://revista.unicuritiba.edu.br/index.php/RevJur/article/view/1842/1214>. Acesso em: 23 abr. 2020. doi:http://dx.doi.org/10.21902/revistajur.2316-753X.v4i45.1842. 